Review

\title{
Neurological Effects of Bisphenol A and its Analogues
}

\author{
Hidekuni Inadera ${ }^{凶}$ \\ Department of Public Health, Faculty of Medicine, University of Toyama, 2630 Sugitani, Toyama 930-0194, Japan \\ $\triangle$ Corresponding author: Hidekuni Inadera, MD, PhD, Department of Public Health, Faculty of Medicine, University of Toyama, 2630 Sugitani, \\ Toyama 930-0194, Japan. Email: inadera@med.u-toyama.ac.jp; Tel: +81-76-434-7275; Fax: +81-76-434-5023 \\ () 2015 Ivyspring International Publisher. Reproduction is permitted for personal, noncommercial use, provided that the article is in whole, unmodified, and properly cited. \\ See http://ivyspring.com/terms for terms and conditions.
}

Received: 2015.07.17; Accepted: 2015.10.12; Published: 2015.10.30

\begin{abstract}
The endocrine disrupting chemical bisphenol A (BPA) is widely used in the production of polycarbonate plastics and epoxy resins. The use of BPA-containing products in daily life makes exposure ubiquitous, and the potential human health risks of this chemical are a major public health concern. Although numerous in vitro and in vivo studies have been published on the effects of BPA on biological systems, there is controversy as to whether ordinary levels of exposure can have adverse effects in humans. However, the increasing incidence of developmental disorders is of concern, and accumulating evidence indicates that BPA has detrimental effects on neurological development. Other bisphenol analogues, used as substitutes for BPA, are also suspected of having a broad range of biological actions. The objective of this review is to summarize our current understanding of the neurobiological effects of BPA and its analogues, and to discuss preventive strategies from a public health perspective.
\end{abstract}

Key words: Bisphenol A, Epigenetics, Neurodevelopment

\section{Introduction}

Bisphenols (BPs) form a large family of chemicals that are utilized to produce polycarbonates and epoxy resins. The most widely used bisphenol is bisphenol A (2,2-bis-(4-hydroxyphenyl)propane; BPA). BPA is a major high-production chemical, with over 6 billion pounds produced each year and over 100 tons are estimated to be released into the atmosphere $[1,2]$. BPA was first synthesized by Dianin as early as 1891 . In the mid-1930s, Dodds et al. discovered the estrogenic properties of BPA during their pursuit of a synthetic estrogen [3]. However, these authors found that diethylstilbestrol (DES) was a far more potent estrogen using a classical estrogenic assay and concluded that the estrogenic potential of BPA was marginal.

Commercial production of BPA did not begin before the early 1950s, when the first epoxy resins were developed. To protect foods and drinks from direct contact with metals, epoxy resins are frequently used in the internal coating of food and beverage containers. BPA is a building block of polycarbonate plastics, including baby bottles [4]. BPA is also used for some dental sealants, carbonless paper for receipts, digital media (CDs and DVDs), electronic equipment, flooring, tableware, and reusable bottles $[1,5,6]$. A recent study reported that BPA was detectable in dust, air particles and water, making exposure widespread [7].

Previous studies have shown that BPA can leach from polycarbonate plastics, epoxy resins and other products in contact with foods and drinks, and as a result, routine oral ingestion of BPA is likely [1, 8-10]. Indeed, one risk assessment study suggested that canned food items contribute to $10-40 \%$ of the daily BPA intake [11]. Because of the potential health risk of BPA, the chemical has been replaced by alternatives. Ironically, these BPA substitutes have also been demonstrated to have detrimental effects on human health. For example, bisphenol F (BPF) and halogenated BPA, used in products for daily life, are suspected of having toxic effects on biological systems $[12,13]$.

Numerous studies on the biological effects of BPA have been published, and its potential human 
health hazards have been extensively summarized [1, 4]. Previous studies have linked BPA exposure to abnormalities of the reproductive system and a higher incidence of cardiovascular disease [14-17]. Along with recent increases in the prevalence of neurobehavioral disorders [18], evidence has been accumulating that BPA can perturb nervous system development. For example, elevated gestational urinary concentrations of BPA have been correlated with adverse behavioral outcomes in children [19-21]. However, many uncertainties remain and controversial discussions are still ongoing.

In this review, recent data on BPA exposure and the potential human health hazards are summarized, focusing on its neurological effects. Knowledge of the effects of other bisphenol analogues on the nervous system is also presented, followed by future directions for the preventive strategies to lessen the impact of these compounds, from a public health perspective.

\section{Human biomonitoring data of BPA}

Exposure data from the biomonitoring of BPA is essential for translating findings from animal studies to human health risk assessment. Although the biological half-life of BPA in humans is estimated to be less than $6 \mathrm{~h}$ [22], long-term daily intake of BPA can lead to steady-state BPA concentrations in human samples [23, 24]. Since 2007, a number of extensive reviews have been published on exposure assessment for BPA [10, 24-26]. Human BPA biomonitoring data has recently been reported [27, 28] and will not be described in detail. Here, brief summary of several key findings from BPA biomonitoring is presented.

Over 10 years ago, a report analyzed human serum samples, and BPA concentrations up to 1.49 $\mathrm{ng} / \mathrm{ml}(6.5 \mathrm{nM})$ were found [29]. BPA has been found not only in adult serum, but also in maternal circulation [26, 30], amniotic and placental fluids [31-33], breast milk [34], and the urine of infants [35]. BPA levels in human amniotic fluid have been measured, and levels as high as $8.3 \mathrm{ng} / \mathrm{ml}(36 \mathrm{nM})$ have been reported [31]. BPA has also been detected in human neonatal blood and cord blood [10]. Indeed, it appears that the human placenta does not act as a barrier to BPA [32]. Abnormal exposure to compounds during critical periods of development can interfere with normal homeostasis and lead to long-term deleterious effects [1]. The fetal brain is especially vulnerable because of an immature xenobiotic-metabolizing system and a relatively permeable blood-brain barrier. Consequently, studies aimed at clarifying the effects of BPA exposure in human neonates and the development of preventive strategies are urgently needed.

Urinary BPA measurements are preferred for evaluating exposure levels because the chemical is concentrated in urine [24]. BPA-glucuronide, a major BPA metabolite in urine, is stable and serves as a useful biomarker of BPA exposure. Administered doses of BPA are completely recovered in urine as BPA-glucuronide within $42 \mathrm{~h}[36,37]$. Thus, the measurement of urinary concentrations of BPA-glucuronide or total BPA in urine is the most appropriate and feasible way to assess daily exposure in humans from all sources [24].

In 2005, the first study to measure total BPA concentrations in a reference population was reported from the Centers for Disease Control (CDC) [38]. BPA was detected in $95 \%$ of the urine samples analyzed, and concentrations up to $5.18 \mathrm{ng} / \mathrm{ml}$ (95th percentile) were reported. The CDC followed this study with a second one, examining spot urine samples from 2,517 Americans $>6$ years of age in the 2003-2004 National Health and Nutrition Examination Survey (NHANES) [39]. BPA was detected in $92.6 \%$ of participants, with concentrations ranging from 0.4 to $149 \mathrm{ng} / \mathrm{ml}$ (with a geometric mean of $2.6 \mathrm{ng} / \mathrm{ml}$ urine). The geometric mean of BPA was $2.49 \mathrm{ng} / \mathrm{ml}$ for the period 2003-2004 and $1.79 \mathrm{ng} / \mathrm{ml}$ for the period 2005-2006 [15], suggesting that exposure levels may have declined recently.

Importantly, the geometric mean urinary concentration of BPA among premature infants undergoing intensive therapeutic medical intervention was one order of magnitude higher than in the general population (30.3 vs. $2.6 \mathrm{ng} / \mathrm{ml}$ urine) [35]. Such a high level of exposure may be due to the use of medical equipment, including medical tubes and bottles. While adults have a high capacity to rapidly metabolize and excrete BPA, the fetus and infant have lower hepatic levels of metabolizing enzymes, and thus are at greater risk from exposure to unconjugated BPA than the adult [40]. Therefore, BPA exposure in fetuses and neonates is of great concern because of the high sensitivity of developing organs. Indeed, the US Food and Drug Administration raised concerns over BPA exposure in fetuses, infants and young children [41]. To avoid potential hazards, Canada became the first country to declare BPA to be a toxic compound and required its removal from all infant formula bottles in 2010. BPA was also banned in infant formula bottles by the European Union in 2011 and by the United States in 2012. In France, the use of BPA in any food or beverage packaging was forbidden from January 2015 [42].

BPA concentrations in biological samples differ among published studies. One possible source of discrepancy may be differences in analytical methodology [24]. At present, the gold standard for measuring BPA is solid-phase extraction coupled with high performance chromatography-isotope dilution tandem 
mass spectrometry with peak focusing [7]. The choice of equipment and containers used to collect and store samples is critical for the accurate assessment of BPA concentrations. A major concern is potential contamination of biological specimens by materials and processes, e.g., by dust containing BPA. In fact, contamination of reagents or solvents with BPA or leaching of BPA from materials used for sampling and sample storage have been reported $[37,43]$. Therefore, a general problem with blood and urine BPA measurements is background contamination of samples, which may interfere with quantitation at low concentrations. Therefore, in future studies, to accurately evaluate the effects of BPA exposure in the general population, large sample size and accurate and sensitive assessment methods devoid of contamination from materials used for sampling and storage are required.

It has been reported that only about $10 \%$ of orally ingested BPA is bioavailable 20 to 30 minutes later [44]. Given the short half-life of orally ingested BPA and the high frequency of detection, continued exposure to human body may be present. The ubiquity of BPA-containing plastics makes human exposure nearly universal. A study of temporal variability found that a single spot urine sample had moderate sensitivity for predicting an individual's tertiary BPA categorization [45]. Other studies have shown that urinary BPA concentrations can vary up to two orders of magnitude within a given day, making it difficult to eliminate exposure misclassification [46, 47]. Thus, multiple urine samples collected over an extended period of time are required for more accurately assessing long-term exposure. Indeed, reproducibility, estimated by the intraclass correlation coefficient, was reported to be only 0.32 for urinary BPA concentrations measured during pregnancy [48]. Braun et al. reported an even lower intraclass correlation coefficient of 0.11 for BPA across three urine samples collected during pregnancy, suggesting the need for repeated urinary BPA measurements during pregnancy for less biased exposure-response estimates [49]. This variability may be a limitation for large-scale epidemiological studies, because multiple sample collection is often not practical. Future studies should consider the importance of collecting multiple or integrated urinary concentration measurements to improve exposure estimation.

\section{Pleiotropic actions of BPA}

In this section, I summarize our current mechanistic understanding of the pleiotropic actions of BPA. BPA is a well-known xenoestrogen [50]. Biochemical assays have examined the kinetics of BPA binding to estrogen receptors (ERs) [51]. BPA was demonstrated to bind both ERa and ER $\beta$, with approximately 10 times higher affinity for ER $\beta$ [50]. Although BPA was considered a weak environmental estrogen, results from several studies have revealed that BPA can stimulate cellular responses at very low concentrations, below the levels where BPA is expected to bind to the classical nuclear ERs [23]. Thus, it is improbable that BPA elicits its effects only through classical ER-dependent nuclear pathways.

Mounting evidence suggests a variety of pathways through which BPA can elicit cellular responses at very low concentrations and with the same or even higher efficiency than $17 \beta$-estradiol (E2) [52-55]. BPA has been shown to bind to a membrane-associated ER and produce non-genomic effects [56] with the same efficacy and potency as E2 [52,54,57]. Indeed, a recent report showed that BPA and E2 have an equimolar activational capacity for ER rapid signaling pathways in human prostaspheres [58]. However, despite this similarity, it has been reported that ligand-dependent differences exist in the ability of the ER to provoke different actions. For example, BPA and E2 induce distinct conformational changes in the tertiary structure of the ER after binding, and have a differential ability to recruit coactivator proteins [59]. Thus, binding affinities of xenoestrogens for ERs may not accurately predict ability to recruit coactivator proteins or subsequent action.

BPA has been reported to have the ability to modify the actions of physiologic estrogens. For example, BPA has a marked inhibitory effect on E2-induced extracellular-signal-regulated kinase (ERK) activity in rat pituitary cells. In these cells, BPA therefore acts as an antiestrogen, although the underlying molecular mechanisms remain to be clarified [60].

Molecular studies have revealed a variety of pathways through which BPA stimulates cellular responses at very low doses. BPA was reported to bind to the aryl hydrocarbon receptor [61] and to the thyroid hormone receptor [62], inhibiting the transcriptional activity induced by triiodothyronine (T3) [63]. A potent antiandrogenic activity of BPA, resulting from its ability to interfere with agonist binding to the androgen receptor, was also reported [64]. In addition, BPA has been found to act as a glucocorticoid receptor agonist [65] and impair insulin homeostasis [66]. BPA also activates the pregnane $X$ receptor [67]. Thus, the net effect of BPA may result from multiple actions on different signaling pathways. The multitude of targets may underlie the pleiotropic effect of BPA on multiple biological systems.

Estrogen-related receptor $\gamma(\mathrm{ERR} \gamma)$ was identified as a BPA target receptor in 2006 [68]. Indeed, BPA binds very strongly to ERRy, with a $\mathrm{Kd}$ of $5.5 \mathrm{nM}$ 
[68-70]. ERRY is expressed very strongly in the mammalian brain during development [71]. ERR $\gamma$ is a nuclear receptor whose natural ligand is not known, but is thought to play a role in the differentiation and maturation of the fetal brain [71]. If BPA can bind to ERRY specifically, the physiological functions of ERRY might be perturbed and neurodevelopmental disorders may ensue, especially when exposure occurs during the critical early periods of nervous system development.

\section{Effects of BPA on neurological systems}

Because of its impact on the endocrine system, BPA was initially examined for effects on sexual dysfunction, malformation, and cancers of reproductive origin. Recent population-based epidemiological studies have linked BPA to metabolic disorders, such as obesity and diabetes, and to cardiovascular disease $[72,73]$. Along with the growth in the production of toxic chemicals, an increase in the prevalence of neurodevelopmental disorders has been observed over the past few decades. Evidence has been accumulating that environmental chemicals, including BPA, can cause neurodevelopmental disorders. Indeed, the National Toxicology Program (NTP) of the United States concluded that "there is some concern for effects on the brain, behavior, and prostate gland in fetuses, infants, and children at current human exposures to BPA". Thus, neurological systems are considered important targets of BPA. In this section, I summarize recent advances in our understanding of the effects of BPA on neurological function.

A number of animal studies reported that BPA exposure during gestational period affects brain development and behaviors (Table 1). Perinatal or neonatal BPA exposure alters brain sexual differentiation [74, 75]. BPA can induce aggression, anxiety, cognitive deficits, and learning-memory impairment [76-80]. BPA can also influence the display of juvenile social behaviors in mice $[81,82]$. Perinatal exposure to BPA increases anxiety-like behavior and elevates dopamine levels in male, but not female, mice [83]. BPA exposure in male rats during lactation is associated with hyperactivity and the degeneration of dopaminergic neurons [84]. BPA exposure during organogenesis and breastfeeding upregulates dopamine receptor function, whereas exposure at other gestational periods does not, suggesting the presence of critical developmental windows of BPA toxicity [85]. In both rodents and nonhuman primates, BPA has adverse effects on the brain even at relatively low exposure levels $[86,87]$.

Table 1 Effects of Bisphenol A on the Nervous System (Animal Studies)

\begin{tabular}{|c|c|c|}
\hline Animal & Major Effects & References \\
\hline \multicolumn{3}{|l|}{ Mice } \\
\hline $2 \mathrm{ng} / \mathrm{g}$ or $20 \mathrm{ng} / \mathrm{g}$ of body weight & Increased aggression in male mice & Kawai et al. (2003) [76] \\
\hline $2 \mathrm{mg} / \mathrm{g}$ diet & Enhanced hyperlocomotion and sensitization to methamphetamine & Suzuki et al. (2003) [143] \\
\hline $25 \mathrm{ng} / \mathrm{kg} /$ day & Decreased number of tyrosine hydroxylase neurons & Rubin et al. (2006) [75] \\
\hline $20 \mu \mathrm{g} / \mathrm{kg} /$ day & Perturbed differentiation and migration of neurons & Nakamura et al. (2006) [99] \\
\hline 2 and $200 \mu \mathrm{g} / \mathrm{kg} /$ day & Increased anxiety-like behavior in female mice & Ryan et al. (2006) [144] \\
\hline $30 \mathrm{ng} / \mathrm{g}$ diet & Enhanced morphine-induced hyperlocomotion and rewarding effect & Narita et al. (2006) [145] \\
\hline $30 \mathrm{ng} / \mathrm{g}$ or $2 \mathrm{mg} / \mathrm{g}$ diet & Memory impairment & Miyagawa et al. (2007) [78] \\
\hline $10 \mu \mathrm{g} / \mathrm{kg} /$ day & Alterations in brain structure & Palanza et al. (2008) [146] \\
\hline $100 \mu \mathrm{g} / \mathrm{kg} /$ day & Anxiolytic-like effect and induction of cognitive deficits & Tian et al. (2010) [79] \\
\hline $50 \mathrm{mg} / \mathrm{kg}$ feed weight & Impact on social behavior and anxiety & Cox et al. (2010) [81] \\
\hline $20 \mu \mathrm{g} / \mathrm{kg} /$ day & Perturbation of neurotransmitter system & Nakamura et al. (2010) [147] \\
\hline $40 \mu \mathrm{g} / \mathrm{kg} /$ day & Changes in nitric oxide production & Martini et al. (2010) [148] \\
\hline $50 \mathrm{mg} / \mathrm{kg}$ feed weight & Perturbed spatial learning abilities and exploratory behaviors & Jasarevic et al. (2011) [149] \\
\hline $250 \mathrm{ng} / \mathrm{kg} /$ day & Increased anxiety-like behavior in males & Matsuda et al. (2012) [83] \\
\hline $2 \mu \mathrm{g} / \mathrm{kg} /$ day & Sex-specific epigenetic disruption in the brain & Kundakovic et al. (2013) [97] \\
\hline $10 \mu \mathrm{g} / \mathrm{kg} /$ day & Increased anxiety in females & Gioiosa et al. (2013) [150] \\
\hline \multicolumn{3}{|l|}{ Rats } \\
\hline $1.5 \mathrm{mg} / \mathrm{kg} /$ day & Disrupted sexual differentiation in the brain & Kubo et al. (2001) [151] \\
\hline $40 \mathrm{mg} / \mathrm{kg} /$ day & Increased estrogen receptor expression in the medial preoptic nucleus & Aloisi et al. (2001) [152] \\
\hline $40 \mu \mathrm{g} / \mathrm{kg} /$ day & Altered brain monoaminergic function & Adriani et al. (2003) [153] \\
\hline $100 \mu \mathrm{g} / \mathrm{kg} /$ day & Changes in gender-dependent memory acquisition & Carr et al. (2003) [154] \\
\hline $15 \mu \mathrm{g} / \mathrm{kg} /$ day & Increased immobility in the forced swim test & Fujimoto et al. (2006) [155] \\
\hline $600 \mu \mathrm{g} / \mathrm{pup} /$ day & Increased spontaneous motor activity & Ishido et al. (2007) [84] \\
\hline $40 \mu \mathrm{g} / \mathrm{kg} /$ day & Increased anxiety and cognitive deficits & Poimenova et al. (2010) [156] \\
\hline $50 \mu \mathrm{g} / \mathrm{kg}$ & $\begin{array}{l}\text { Increased oxytocin-immunoreactive cell number } \\
\text { in the female rat paraventricular nucleus }\end{array}$ & Adewale et al. (2011) [103] \\
\hline $20 \mu \mathrm{g} / \mathrm{day}$ & Hyperactivity & Ishido et al.(2011) [157] \\
\hline $2 \mu \mathrm{g} / \mathrm{kg} /$ day & Increased hyperactivity and decreased attention & Zhou et al. (2011) [158] \\
\hline $50 \mu \mathrm{g} / \mathrm{kg} /$ day & Enhanced short-term passive avoidance memory & Xu et al. (2011) [159] \\
\hline $24 \mu \mathrm{g} / \mathrm{kg} /$ day & Enhanced depressive-like behavior & Fujimoto et al. (2013) [160] \\
\hline \multicolumn{3}{|l|}{ Other Species } \\
\hline \multicolumn{3}{|l|}{ African green monkeys } \\
\hline $50 \mu \mathrm{g} / \mathrm{kg} /$ day & Perturbation of the synaptogenic effect of estradiol & Leranth et al.(2008) [86] \\
\hline cynomolgus monkeys & Altered behavior and sexual differentiation & Nakagami et al. (2009) [87] \\
\hline
\end{tabular}


Table 2 Association Between Prenatal Exposure to BPA and Neurological Development (Human Studies)

\begin{tabular}{|c|c|c|}
\hline Subjects & Major Findings & References \\
\hline Girls 2 years of age & Increased hyperactivity and aggression scores & Braun et al. (2009) [19] \\
\hline Girls 3 years of age & Association with worse behavior & Braun et al. (2011) [20] \\
\hline Infants at 5 weeks & No association with infant behavior & Yolton et al. (2011) [89] \\
\hline Infants 7 and 9 years of age & No association with social impairment & Midovnik et al. (2011) [90] \\
\hline Boys 3-5 years of age & Association with increased aggressive behavior and emotional reactivity & Perera et al. (2012) [88] \\
\hline Boys 7 years of age & Increased symptoms of depression and anxiety & Harley et al. (2013) [21] \\
\hline Infants $6-10$ years of age & Increased behavior problems in boys but not girls & Evans et al. (2014) [161] \\
\hline
\end{tabular}

In humans, accumulating evidence suggests that early life exposure to BPA impacts neural development (Table 2). BPA exposure during gestation is associated with hyperactivity and aggression in 2-year-old girls [19] and with anxiety and depression in 3-year-old girls [20]. Importantly, childhood urinary BPA concentrations were less important predictors than gestational BPA exposure [20]. Perera et al. found that maternal urinary BPA concentrations during pregnancy were associated with increased aggressive behavior and emotional reactivity in boys between 3 and 5 years of age [88]. Harley et al. reported that prenatal urinary BPA concentrations were associated with increased internalizing problems in boys, but not girls [21]. However, some studies found no significant associations between gestational exposure to BPA and infant neurobehavioral measures [89]. Miodovnik et al. reported prenatal BPA exposure was not associated with childhood social impairment in 7- and 9-year-olds [90]. Although the source of these discrepancies remains obscure, low levels of exposure may be below a threshold at which neurobehavioral effects manifest. Alternatively, the discrepancies may reflect differences in study populations or methodology for exposure assessment. In addition, the behavioral effects of BPA exposure may manifest differentially depending on both child age and time of exposure. Recently, one human cell culture study showed that BPA significantly decreased potassium chloride cotransporter 2 (Kcc2) mRNA expression in developing cortical neurons, suggesting that BPA delays the perinatal chloride shift [91]. This may have relevance for our understanding of the mechanisms of BPA neurodevelopmental toxicity.

Intriguingly, BPA has sex-specific effects on the expression of behaviors associated with anxiety, activity and sociality [82, 92]. Many behaviors and neuroendocrine pathways are sexually dimorphic. Exposure to BPA that disrupts hormone function during critical periods of prenatal development may perturb sex-specific or hormonally regulated behaviors. Disruptions in behaviors may lead to reduced social adaptation and impaired responsiveness to environmental demands. Thus, the sex of the child may impact the association between prenatal BPA exposure and externalizing behaviors. Indeed, a sex-specific effect of perinatal BPA exposure on hypothalamic morphology was reported [93]. BPA exposure affects exploratory activity and behavior in females, but only minimally disrupts partner preference formation [94].

Gonadal hormones are known to influence the sexual differentiation of the brain. Therefore, exposure to endocrine disrupters which affect gonadal hormone levels may contribute to sex-specific behavioral changes [95]. Galloway et al. found that urinary BPA was correlated with serum concentrations of total testosterone [96]. Thus, alterations in gonadal hormone levels provoked by BPA exposure may perturb sex-dependent neurobehaviors. Interestingly, a recent report showed that prenatal BPA treatment results in a sex-specific disruption of epigenetic pathways in the brain [97]. Future studies should examine whether males and females have differential levels of susceptibility to BPA at different periods of development.

The molecular mechanisms mediating the effects of BPA on the nervous system are beginning to be clarified. Disruption of maternal thyroid or gonadal hormones critical for normal development may underlie the effects of BPA. Chevrier et al. found that BPA exposure during pregnancy was associated with decreased total thyroxine (T4) in pregnant women and reduced thyroid stimulating hormone (TSH) in male neonates [98]. Furthermore, prenatal exposure to low doses of BPA in pregnant mice alters thyroid receptor expression in the fetal neocortex [99]. These findings suggest that perinatal hypothyroxinemia caused by BPA exposure during pregnancy may underlie some of the neurological deficits in offspring.

Early life exposure to BPA has been shown to affect the dopamine system [100]. Gestational exposure to BPA reduces the number of midbrain dopamine neurons in monkeys [101]. It has been reported that tyrosine hydroxylase, the rate-limiting enzyme in dopamine synthesis, is affected by BPA [84]. Thus, an alteration of the dopaminergic system may account for some of the neurological deficits associated with BPA exposure, such as anxiety-like behaviors [81, 83]. Additionally, developmental exposure to BPA alters the organization and function of the oxytocin (OT)/vasopressin (AVP) system [102, 103], and may 
thereby impact behaviors regulated by associated pathways [94, 102]. Furthermore, prenatal exposure to BPA affects fetal neocortical development by accelerating neuronal differentiation and migration during the early embryonic stage [104].

Exposure to even low doses of BPA during gestation has been shown to have long-lasting transgenerational effects on brain mRNA expression and social behaviors [105]. The prenatal period is uniquely vulnerable to the effects of BPA on brain development. These effects may be generated via a heritable epigenetic process, such as DNA methylation [106, 107]. Indeed, previous studies on BPA-induced alterations of the methylome suggest that multiple genes in tissues derived from the various germ layers are differentially methylated [108, 109]. BPA exposure induces persistent sex-specific epigenetic changes in the brain that possibly underlie the long-term effects of BPA on brain function and behavior [97, 110], and which may have transgenerational effects as well.

Although the associated molecular mechanisms remain unclear, numerous studies suggest that BPA can alter brain development, and thus may affect the acquisition or progression of neurological disorders. In addition, exposure to BPA may affect behavior in multiple generations through epigenetic pathways in animal models [111]. However, in humans, longitudinal studies on the cause-effect relationship of environmental chemicals and neurodevelopmental disorders are lacking. Neurodevelopmental disorders tend to be diagnosed only when a child is several years of age, thereby posing a methodological hurdle for cause-effect studies. There is a high prevalence of neurodevelopmental disorders in children, and behavioral problems in childhood have been shown to predict behavioral problems in adolescence and adulthood [112]. Consequently, there is a great need for studies on childhood exposure to BPA and those aimed at reducing the risk of neurodevelopmental disorders.

\section{Bisphenol A analogues}

Because of the biological effects of BPA, there has been a gradual shift to using bisphenol analogues. Several chemicals that are structurally similar to BPA are presently used in the manufacture of resins and plastics, as substitutes or replacements for BPA. The biological actions of bisphenol analogues are beginning to be clarified.

As described in the previous section, estrogens affect normal brain function and behavior [113, 114]. A study examined the estrogenic activity of BPA and related compounds using an estrogen response element reporter gene assay in MCF-7 human breast cancer cells [12]. Among the 19 BPA-related com- pounds tested, several, including tetrachlorobisphenol A (TCBPA), bisphenol AF (BPAF), bisphenol $\mathrm{B}$ (BPB), 2-(4-hydroxyphenyl)-2-phenylpropane (HPP), 1,1-bis(4-hydroxyphenyl) cyclohexane) $(\mathrm{BPCH}), 4$-hydroxydiphenyl-methane (HDM) and 3,3'-dimethyl-bisphenol A (DMBPA), were found to have higher estrogenic activity than BPA [12]. Thus, these estrogenic BPs may cause neurodevelopmental disorders by disrupting ER-dependent pathways.

The production and use of (bis-(4hydroxyphenyl)sulfone) (bisphenol S; BPS) has recently risen in many countries [115]. BPS contains two phenolic rings connected by sulfur and is more heat-stable than BPA [116]. It was introduced into consumer goods, such as canned foods and cash-register receipts. BPS is often used as a BPA alternative in "BPA-free" thermal printing paper. BPS has been found in thermal receipt papers at concentrations comparable to those of BPA [117]. Widespread exposure of the general population to BPS has been demonstrated in various countries. For example, BPS in the urine has been detected in $81 \%$ of 315 people sampled in American and Asian populations, with levels ranging from 0.02 to $21 \mathrm{ng} / \mathrm{ml}(0.8-84 \mathrm{nM})$ [118]. BPA and BPS are about the same size and have similar phenolic ring structures, and therefore, BPS has been suspected to function as a xenoestrogen [119]. Indeed, an assay for estrogenic activity showed that BPS has a weak estrogenic effect [120]. However, the cell biological effects of BPA and BPS appear to differ [121]. BPS, at low-dose ranges likely to be present in food items, appeared to interact predominantly with the cell-membrane ER and affect nongenomic signaling, leading to potential consequences for cell function [122]. A recent study showed that both BPS and BPA influence hypothalamic development [123]. Given the disrupting effects of BPS and its higher resistance to environmental degradation in comparison to BPA [124], the proposal to utilize BPS instead of BPA in various products should be viewed with caution.

Bisphenol AF (BPAF), a fluorinated derivative of BPA, is used in polycarbonate copolymers in high-temperature composites, electronic materials, and specialty polymer applications [125]. BPAF binds to ERa more strongly than BPA and has a much higher affinity for ERa than ERR $\gamma$ [70]. BPAF is a strong ligand for both ERa and ER $\beta$, with a 3-fold greater preference for the latter [126]. However, interestingly, BPAF is a full agonist for ERa, but an antagonist for ER $\beta[125,126]$. Thus, BPAF perturbs physiological processes regulated by estrogen and may have significant adverse effects on the nervous system.

Bisphenol-A diglycidyl ether (BADGE) is an an- 
alog of BPA that is used in manufacturing coating and resins, and can leach from packaging materials into food. BADGE induces adipogenesis in multipotent mesenchymal stromal stem cells, as well as in 3T3-L1 adipocytes at low nanomolar concentrations comparable to those observed in human biomonitoring [127]. The effects of BADGE appear to be mediated, at least in part, by peroxisome proliferator-activated receptor $Y$ (PPARY) [128, 129]. PPARY is a member of the nuclear receptor superfamily and is involved in the pathogenesis of obesity and diabetes [130]. Interestingly, brain PPARY regulates energy balance, and its activation may lead to hyperphagia and an increase in adipose tissue mass [131, 132]. Thus, BADGE may function as an obesogen via central nervous system.

Environmental as well as human exposure data indicate that halogenated BPs are emerging contaminants [133]. Analogs of BPA where the phenolic moieties are substituted with halogens $(\mathrm{Br}$ or $\mathrm{Cl})$ are used as flame retardants. Approximately 200,000 tons of tetrabromobisphenol A (TBBPA) are produced annually, and used to protect computer boards and other electric equipment [133]. Tetrachlorobisphenol A (TCBPA) is also used as a flame retardant. The presence of TCBPA and other chlorinated analogs (mono-, di- and triCBPA) in environmental samples has been unequivocally demonstrated [134]. Their presence in human samples, including mother's milk, has also been demonstrated $[2,135,136]$. Significant levels of TBBPA are found in human cord blood $(200 \mathrm{pg} / \mathrm{g}$ fresh weight) and maternal milk (0.1-37.4 ng/g lipid weight), indicating both prenatal and postnatal exposure [135]. Not all halogenated BPA analogs are ER agonists. In general, the greater the number of bromine atoms, the weaker the ER agonism [129]. TCBPA and BPA display full agonistic activity towards ER $\alpha$, with a 1,000 to 10,000-fold lower potency than E2 [128]. While these analogs show marginal estrogenicity in assays, they bind with stronger affinity to PPAR $\gamma$ than BPA $[128,129]$. Thus, these halogenated BPA analogs may contribute to onset and disease progression via PPAR $\gamma$, similar to BADGE.

Current knowledge on the biological and potential toxicological effects of BPA analogues, especially on the nervous system, is limited. Moreover, relatively little is known about the biological processing of BPA analogues or the bioactivity of their metabolites, and in vivo studies are lacking. Some BPA substitutes appear to be more resistant to environmental degradation than BPA [124, 137]. Thus, the use of BPA analogues should be carried out with caution, especially until effective risk assessment is conducted.

\section{Future perspectives}

Although numerous studies have been pub- lished on the effects of BPA on neurobiological functions, the underlying mechanisms remain unclear. BPA displays non-monotonic dose-response functions, and very different effects at environmentally relevant doses compared with higher exposures [4]. It is evident that BPA does not function solely as an estrogen mimic. Furthermore, it is unclear why BPA has such wide-ranging effects on neurobiological systems at low concentrations. Detailed mechanistic studies are needed to clarify the effects of chronic low-dose BPA exposure.

Alterations in gene expression induced by fetal exposure to BPA have been demonstrated, suggesting a role for epigenetic regulation, such as altered DNA methylation and miRNA expression [138-140]. The contribution of epigenetics to phenotype is an exciting research topic. Because of the relatively new understanding of the role of miRNAs in gene regulation, the direct targets of many specific miRNAs and their roles in early neurodevelopment are largely unknown. Nonetheless, altered miRNA expression may be a potential mechanism of BPA action, but needs further study.

Even low doses of BPA can trigger major neurological perturbations when exposure occurs during critical developmental windows [1, 141]. Timing of exposure is a key factor determining potential developmental and behavioral consequences. Understanding the factors impacting the neurotoxicity of BPs during pregnancy is essential for preventing the adverse neurological effects of these compounds. Studies are needed to more accurately determine the critical windows of developmental exposure, to clarify gender-specific effects and resolve the molecular and cell biological impact of these compounds. The general population may experience chronic low-dose exposures requiring improved biomarkers for detection of low-dose toxicity. This will be especially important for identifying sensitive subpopulations and for discriminating the effects of BPs from those of other environmental contaminants.

Despite widespread human exposure in developed countries, there are a limited number of epidemiological studies on the association of BPs with neurodevelopmental disorders. In particular, large-scale prospective studies are lacking to validate findings from animal studies. Future research should include prospective, longitudinal cohort studies in which exposure to BPs are assessed in relation to neurodevelopmental outcome. In the real world, environmental exposure is rarely due to a single chemical, but rather involve complex chemical mixtures. Indeed, a recent study found that BPA concentrations were correlated with other EDC metabolite concentrations (such as phthalates) in urine from the prenatal 
stage up to 7 years of age [142]. Given the ubiquitous presence of BPs and other EDCs in the environment, it is not unexpected that they would be widely detectable in the general population. The effects of cumulative exposure on neurodevelopmental outcomes are a concern, which need to be investigated further. Despite the absence of epidemiological studies, concerns over adverse effects of BPA and its analogues are warranted given the unique vulnerability of the developing fetus and neonate. Thus, caution is recommended in the use of BP compounds, particularly until further data are obtained from risk assessment studies.

\section{Abbreviations}

BPs: bisphenols; BPA: bisphenol A; DES: diethylstilbestrol; E2: $17 \beta$ estradiol; ER: estrogen receptor; ERR: estrogen-related receptor; PPAR: peroxisome proliferator-activated receptor

\section{Competing Interests}

The authors have declared that no competing interest exists.

\section{References}

1. Vandenberg LN, Maffini MV, Sonnenschein C, et al. Bisphenol-A and the great divide: a review of controversies in the field of endocrine disruption. Endocr Rev. 2009; 30: 75-95.

2. Jimenez-Diaz I, Zafra-Gomez A, Ballesteros O, et al. Determination of Bisphenol A and its chlorinated derivatives in placental tissue samples by liquid chromatography-tandem mass spectrometry. J Chromatogr B Analyt Technol Biomed Life Sci. 2010; 878: 3363-3369.

3. Dodds EC, Lawson W. Synthetic estrogenic agents without the phenanthrene nucleus. Nature. 1936; 137:996.

4. Rubin BS. Bisphenol A: an endocrine disruptor with widespread exposure and multiple effects. J Steroid Biochem Mol Biol. 2011; 127: 27-34.

5. Vogel SA. The politics of plastics: The making and unmaking of bisphenol a "safety". Am J Public Health. 2009; 99 (Suppl 3): S559-S556.

6. Biedermann S, Tschudin P, Grob K. Transfer of bisphenol A from thermal printer paper to the skin. Anal Bioanal Chem. 2010; 398:571-576.

7. Asimakopoulos AG, Thomaidis NS, Koupparis MA. Recent trends in biomonitoring of bisphenol A, 4-t-octylphenol, and 4-nonylphenol. Toxicol Lett. 2012; 210: 141-154.

8. Kang JH, Kondo F, Katayama Y. Human exposure to bisphenol A. Toxicology. 2006; 226: 79-89.

9. Wilson NK, Chuang JC, Morgan MK, et al. An observational study of the potential exposures of preschool children to pentachlorophenol, bisphenol-A, and nonylphenol at home and daycare. Environ Res. 2007; 103: 9-20.

10. Vandenberg LN, Hauser R, Marcus M, et al. Human exposure to bisphenol A (BPA). Reprod Toxicol. 2007; 24: 139-177.

11. Von Goetz N, Wormuth $\mathrm{M}$, Scheringer $\mathrm{M}$, et al. Bisphenol a: how the most relevant exposure sources contribute to total consumer exposure. Risk Anal. 2010; 30: 473-487.

12. Kitamura S, Suzuki T, Sanoh S, et al. Comparative study of the endocrine-disrupting activity of bisphenol A and 19 related compounds. Toxicol Sci. 2005; 84:249-259.

13. Delfosse V, Grimaldi M, Pons JL, et al. Structural and mechanistic insights into bisphenols action provide guidelines for risk assessment and discovery of bisphenol A substitutes. Proc Natl Acad Sci USA. 2012; 37: 14930-14935.

14. Lang IA, Galloway TS, Scarlett A, et al. Association of urinary bisphenol A concentration with medical disorders and laboratory abnormalities in adults. JAMA. 2008; 300: 1303

15. Melzer D, Rice NE, Lewis C, et al. Association of urinary bisphenol A concentration with heart disease: evidence from NHANES 2003/06. PLoS One 2010; 5: e8673.

16. Melzer D, Osborne NJ, Henley WE, et al. Urinary bispehnol A concentration and risk of future coronary artery disease in apparently healthy men and women. Circulation. 2012; 125:1482-1490.

17. Melzer D, Gates P, Osborne NJ, et al. Urinary bispehnol A concentration and angiography-defined coronary artery stenosis. PLos One. 2012; 7: e43378.
18. Visser SN, Danielson ML, Bitsko RH, et al. Trends in the parent-report of health care provider-diagnosed and medicated attention-deficit/hyperactivity disorder: United States, 2003-2011. J Am Acad Child Adolesc Psychiatry. 2014; 53: 34-46.

19. Braun JM, Yolton K, Dietrich KN, et al. Prenatal bisphenol A exposure and early childhood behavior. Environ Health Perspect. 2009; 117: 1945-1952.

20. Braun JM, Kalkbrenner AE, Calafat AM, et al. Impact of early-life bisphenol A exposure on behavior and executive function in children. Pediatrics. 2011;128: 873-882.

21. Harley KG, Gunier RB, Kogut K, et al. Prenatal and early childhood bisphenol A concentrations and behavior in school-aged children. Environ Res. 2013; 126: 43-50.

22. Volkel W, Colnot T, Csanady GA, et al. Metabolism and kinetics of bisphenol A in humans at low doses following oral administration. Chem Res Toxicol. 2002; 15: 1281-1287.

23. Welshons WV, Nagel SC, vom Saal FS. Large effects from small exposure. III. Endocrine mechanisms mediating effects of bisphenol A at levels of human exposure. Endocrinology. 2006; 147 (6 suppl): S56-S69.

24. Dekant W, Volkel W. Human exposure to bisphenol A by biomonitoring: methods results and assessment of environmental exposures. Toxicol Appl Pharmacol. 2008; 228:114-134.

25. Diamanti-Kandarakis E, Bourguignon JP, Giudice LC, et al. Endocrine-disrupting chemicals: an Endocrine Society scientific statement. Endocr Rev. 2009; 30: 293-342.

26. Vandenberg LN, Chahoud I, Heindel JJ, et al. Urinary, circulating, and tissue biomonitoring studies indicate widespread exposure to bisphenol A. Environ Health Perspect. 2010; 118: 1055-1070.

27. Geens T, Aerts D, Berthot C, et al. A review of dietary and non-dietary exposure to bisphenol-A. Food Chem Toxicol. 2012; 50:3725-3740.

28. Vandenberg LN, Chahoud I, Heindel JJ, et al. Urinary, circulating, and tissue biomonitoring studies indicate widespread exposure to bisphenol A. Cien Saude Colet. 2012; 17: 407-434.

29. Takeuchi T, Tsutsumi O. Serum bisphenol A concentrations showed gender differences, possibly linked to androgen levels. Biochem Biophys Res Commun. 2002; 291: 76-78.

30. Padmanabhan V, Siefert K, Ransom S, et al. Maternal bisphenol-A levels at delivery: a looming problem? J Perinatol. 2008; 28: 258-263.

31. Ikezuki $Y$, Tsutsumi O, Takai $Y$, et al. Determination of bisphenol A concentrations in human biological fluids reveals significant early prenatal exposure. Hum Reprod. 2002; 17:2839-2841.

32. Schonfelder G, Wittfoht W, Hopp H, et al. Parent bisphenol A accumulation in the human maternal-fetal-placental unit. Environ Health Perspect. 2002; 110: A703-A707

33. Edlow AG, Chen M, Smith NA, et al. Fetal bisphenol A exposure: concentration of conjugated and unconjugated bisphenol $\mathrm{A}$ in amniotic fluid in the second and third trimesters. Reprod Toxicol. 2012; 34: 1-7.

34. Sun Y, Irie M, Kishikawa N, et al. Determination of bisphenol A in human breast milk by HPLC with column-switchnig and fluorescence detection. Biomed Chromatogr. 2004; 18: 501-507.

35. Calafat AM, Weuve J, Ye X, et al. Exposure to bisphenol A and other phenols in neonatal intensive care unit premature infants. Environ Health Perspect. 2009; 117: 639-644.

36. Tsukioka T, Terasawa J, Sato S, et al. Development of analytical method for determining trace amounts of BPA in urine samples and estimation of exposure to BPA. J Environ Chem. 2004; 14: 57-63.

37. Volkel W, Bittner N, Dekant W. Quantitation of bisphenol A and bisphenol A glucuronide in biological samples by high performance liquid chromatography-tandem mass spectrometry. Drug Metab Dispos. 2005; 33: 1748-1757.

38. Calafat AM, Kuklenyik Z, Reidy JA, et al. Urinary concentrations of bisphenol A and 4-nonylphenol in a human reference population. Environ Health Perspect. 2005; 113:391-395.

39. Calafat AM, Ye X, Wong LY, et al. Exposure of the U.S. population to bisphenol A and 4-tertiary-octylphenol: 2003-2004. Environ Health Perspect. 2008; 116:39-44.

40. Nahar MS, Liao C, Kannan K, et al. Fetal liver bisphenol A concentrations and biotransformation gene expression reveal variable exposure and altered capacity for metabolism in humans. J Biochem Mol Toxicol. 2013; 27: 116-123.

41. [Internet] US Food, Drug Administration (USFDA). Update on Bisphenol A Use in Food Contact Applications. http://www.fda.gov/NewsEvents/ PublicHealthFocus/ucm197739.htm2010.

42 Eladak S, Grisin T, Moison D, et al. A new chapter in the bisphenol A story: bisphenol $\mathrm{S}$ and bisphenol $\mathrm{F}$ are not safe alternatives to this compound. Fertil Steril. 2015; 103: 11-21.

43. Fujimaki K, Arakawa C, Yoshinaga J, et al. Estimation of intake level of bisphenol A in Japanese pregnant women based on measurement of urinary excretion level of the metabolite. Jpn J Hyg. 2004; 59:403-408.

44. Gerona RR, Woodruff TJ, Dickenson CA, et al. Bisphenol-A (BPA), BPA glucuronide, and BPA sulfate in midgestation umbilical cord serum in northern and central California population. Environ Sci Technol. 2013; 47: 12477-12485.

45. Mahalingaiah S, Meeker JD, Pearson KR, et al. Temporal variability and predictors of urinary bisphenol A concentrations in men and women. Environ Health Perspect. 2008; 116:173-178. 
46. Ye X, Wong LY, Bishop AM, et al. Variability of urinary concentrations of bisphenol A in spot samples, first morning voids, and 24-hour collections. Environ Health Perspect. 2011; 119: 983-988.

47. Snijder CA, Heederik D, Pierik FH, et al. Fetal growth and prenatal exposure to bisphenol A: the generation R study. Environ Health Perspect. 2013; 121: 393-398.

48. Jusko TA, Shaw PA, Snijder CA, et al. Reproducibility of urinary bisphenol A concentrations measured during pregnancy in the Generation R Study. J Expo Sci Environ Epidemiol. 2014; 24:532-536.

49. Braun JM, Kalkbrenner AE, Calafat AM, et al. Variability and predictors of urinary bisphenol A concentrations during pregnancy. Environ Health Perspect. 2011; 119: 131-137.

50. Kuiper GG, Lemmen JG, Carlsson B, et al. Interaction of estrogenic chemicals and phytoestrogens with estrogen receptor beta. Endocrinology. 1998; 139: 4252-4263.

51. Gould JC, Leonard LS, Maness SC, et al. Bisphenol A interacts with the estrogen receptor $\alpha$ in a distinct manner from estradiol. Mol Cell Endocrinol. 1998; 142: 203-214.

52. Alonso-Magdalena $\mathrm{P}$, Laribi $\mathrm{O}$, Ropero $\mathrm{AB}$, et al. Low doses of bisphenol $\mathrm{A}$ and diethylstilbestrol impair $\mathrm{Ca} 2+$ signals in pancreatic alpha-cells through a nonclassical membrane estrogen receptor within intact islets of Langerhans. Environ Health Perspect. 2005; 113:969-977.

53. Alonso-Magdalena P, Morimoto S, Ripoll C, et al. The estrogenic effect of bisphenol A disrupts pancreatic beta-cell function in vivo and induces insulin resistance. Environ Health Perspect. 2006; 114:106-112.

54. Hugo ER, Brandebourg TD, Woo JG, et al. Bisphenol A at environmentally relevant doses inhibits adiponectin release from human adipose tissue explants and adipocytes. Environ Health Perspect. 2008; 116:1642-1647.

55. Zsarnovszky A, Le HH, Wang HS, et al. Ontogeny of rapid estrogen-mediated extracellular signal-regulated kinase signaling in the rat cerebellar cortex: potent nongenomic agonist and endocrine disrupting activity of the xenoestrogen bisphenol A. Endocrinology. 2005; 146:5388-5396.

56. Wetherill YB, Akingbemi BT, Kanno J, et al.. In vitro molecular mechanisms of bisphenol A action. Reprod Toxicol. 2007; 24: 178-198.

57. Wozniak AL, Bulayeva NN, Watson CS. Xenoestrogens at picomolar to nanomolar concentrations trigger membrane estrogen receptor-alpha-mediated $\mathrm{Ca} 2+$ fluxes and prolactin release in GH3/B6 pituitary tumor cells. Environ Health Perspect. 2005; 113: 431-439.

58. Prins GS, Hu WY, Shi GB, et al. Bisphenol A promotes human prostate stem-progenitor cell self-renewal and increases in vivo carcinogenesis in human prostate epithelium. Endocrinology. 2014; 155:805-817.

59. Routledge EJ, White R, Parker MG, et al. Differential effects of xenoestrogens on coactivator recruitment by estrogen receptor (ER) alpha and ERbeta. J Biol Chem. 2000; 275: 35986-35993.

60. Jeng YJ, Watson CS. Combinations of physiologic estrogens with xenoestrogens alter ERK phosphorylation profiles in rat pituitary cells. Environ Health Perspect. 2011; 119: 104-112.

61. Bonefeld-Jorgensen EC, Long M, Hofmeister MV, et al. Endocrine-disrupting potential of bisphenol A, bisphenol A dimethacrylate, 4-n-nonylphenol, and 4-n-octylphenol in vitro: new data and a brief review. Environ Health Perspect. 2007; 115 (Suppl.1): 69-76.

62. Zoeller RT, Bansal R, Parris C. Bisphenol A, an environmental contaminant that acts as a thyroid hormone receptor antagonist in vitro, increases serum thyroxine, and alters RC3/neurogranin expression in the developing rat brain. Endocrinology. 2005; 146:607-612.

63. Moriyama K, Tagami T, Akamizu T, et al. Thyroid hormone action is disrupted by bisphenol A as an antagonist. J Clin Endocrinol Metab. 2002; 87: $5185-5190$

64. Lee HJ, Chattopadhyay S, Gong EY, et al. Antiandrogenic effects of bisphenol A and nonylphenol on the function of androgen receptor. Toxicol Sci. 2003; 75: 40-46.

65. Prasanth GK, Divya LM, Sadasivan C. Bisphenol-A can bind to human glucocorticoid receptor as an agonist: an in silico study. J Appl Toxicol. 2010; 30: 769-774.

66. Alonso-Magdalena P, Vieira E, Soriano S, et al. Bisphenol A exposure during pregnancy disrupts glucose homeostasis in mothers and adult male offspring. Environ Health Perspect. 2010; 118:1243-1250.

67. Sui Y, Ai N, Park SH, et al. Bisphenol A and its analogues activate human pregnane X receptor. Environ Health Perspect. 2012; 120:399-405.

68. Takayanagi S, Tokunaga T, Liu X, et al. Endocrine disruptor bisphenol A strongly binds to human estrogen-related receptor $\gamma($ ERR $\gamma)$ with high constitutive activity. Toxicol Lett. 2006; 167:95-105.

69. Matsushima A, Kakuta Y, Teramoto T, et al. Structural evidence for endocrine disruptor bisphenol A binding to human nuclear receptor ERR $\gamma$. J Biol Chem. 2007; 142: 517-524.

70. Okada H, Tokunaga T, Liu X, et al. Direct evidence revealing structural elements essential for the high binding ability of bisphenol A to human estrogen-related receptor-gamma. Environ Health Perspect. 2008; 116: 32-38.

71. Heard DJ, Norby PL, Holloway J, et al. Human ERR $\gamma$, a third member of the estrogen receptor-related receptor (ERR) subfamily of orphan nuclear receptors: tissue-specific isoforms are expresses during development and in the adult. Mol Endocrinol. 2000; 14: 382-392.

72. Shankar A, Teppala S. Relationship between urinary bisphenol A levels and diabetes mellitus. J Clin Endocrinol Metab. 2011; 96: 3822-3826.
73. Wang $\mathrm{T}$, Li M, Chen $\mathrm{B}$, et al. Urinary bisphenol A (BPA) concentration associates with obesity and insulin resistance. J Clin Endocrinol Metab. 2012; 97: E223-E227.

74. Patisaul HB, Fortino AE, Polston EK. Neonatal genistein or bisphenol-A exposure alters sexual differentiation of the AVPV. Neurotoxicol Teratol. 2006; 28: 111-118.

75. Rubin BS, Lenkowski JR, Schaeberle CM, et al. Evidence of altered brain sexual differentiation in mice exposed perinatally to low, environmentally relevant levels of bisphenol A. Endocrinology. 2006; 147: 3681-3691.

76. Kawai K, Nozaki T, Nishikata H, et al. Aggressive behavior and serum testosterone concentration during the maturation process of male mice: the effects of fetal exposure to bisphenol A. Environ Health Perspect. 2003; 111: 175-178.

77. Porrini S, Belloni V, Della Seta D, et al. Early exposure to a low dose of bisphenol A affects socio-sexual behavior of juvenile female rats. Brain Res Bull. 2005; 65:261-266

78. Miyagawa K, Narita M, Narita M, et al. Memory impairment associated with a dysfunction of the hippocampal cholinergic system induced by prenatal and neonatal exposure to bisphenol-A. Neurosci Lett. 2007; 418: 236-241.

79. Tian YH, Baek JH, Lee SY, et al. Prenatal and postnatal exposure to bisphenol a induces anxiolytic behaviors and cognitive deficits in mice. Synapse. 2010; 64:432-439.

80. $\mathrm{Xu} \mathrm{XH}$, Zhang J, Wang YM, et al. Perinatal exposure to bisphenol-A impairs learning-memory by concomitant down-regulation of N-methyl-D-aspartate receptors of hippocampus in male offspring mice. Horm Behav. 2010; 58:326-333.

81. Cox KH, Gatewood JD, Howeth C, et al. Gestational exposure to bisphenol A and cross-fostering affect behaviors in juvenile mice. Horm Behav. 2010; 58:754-761.

82. Wolstenholme JT, Taylor JA, Shetty SR, et al. Gestational exposure to low dose bisphenol A alters social behavior in juvenile mice. PLoS One. 2011; 6:e25448.

83. Matsuda S, Matsuzawa D, Ishii D, et al. Effects of perinatal exposure to low dose of bisphenol A on anxiety like behavior and dopamine metabolites in brain. Prog Neuropsychopharmacol Biol Psychiatry. 2012; 39: 273-279.

84. Ishido M, Yonemoto J, Morita M. Mesencephalic neurodegeneration in the orally administered bisphenol A-caused hyperactive rats. Toxicol Lett. 2007; 173: 66-72.

85. Narita M, Miyagawa $K$, Mizuo $K$, et al. Changes in central dopaminergic systems and morphine reward by prenatal and neonatal exposure to bisphenol-A in mice: evidence for the importance of exposure period. Addict Biol. 2007; 12: 167-172

86. Leranth C, Hajszan T, Szigeti-Buck K, et al. Bisphenol A prevents the synaptogenic response to estradiol in hippocampus and prefrontal cortex of ovariectomized nonhuman primates. Proc Natl Acad Sci USA. 2008; 105: 14187-14191.

87. Nakagami A, Negishi T, Kawasaki K, et al. Alterations in male infant behaviors towards its mother by prenatal exposure to bisphenol A in cynomolgus monkeys (Macaca fascicularis) during early suckling period. Psychoneuroendocrinology. 2009; 34: 1189-1197.

88. Perera F, Vishnevetsky J, Herbstman JB, et al. Prenatal bisphenol a exposure and child behavior in an inner-city cohort. Environ Health Perspect. 2012; 120: 1190-1194.

89. Yolton $\mathrm{K}, \mathrm{Xu} \mathrm{Y}$, Strauss D, et al. Prenatal exposure to bisphenol A and phthalates and infant neurobehavior. Neurotoxicol Teratol. 2011;33:558-566.

90. Midovnik A, Engel SM, Zhu C, et al. Endocrine disruptors and childhood social impairment. Neurotoxicology. 2011; 32: 261-267.

91. Yeo M, Berglund K, Hanna M, et al. Bisphenol A delays the perinatal chloride shift in cortical neurons by epigenetic effects on the Kcc2 promoter. Proc Natl Acad Sci USA. 2013; 110:4315-4320.

92. Williams SA, Jasarevic E, Vandas GM, et al. Effects of developmental bisphenol A exposure on reproductive-related behaviors in California mice (Peromyscus californicus): a monogamous animal model. PLoS One. 2013; 8:e55698.

93. McCaffrey KA, Jones B, Mabrey N, et al. Sex specific impact of perinatal bisphenol A (BPA) exposure over a range of orally administered doses on rat hypothalamic sexual differentiation. Neurotoxicology. 2013; 36: 55-62.

94. Sullivan AW, Beach EC, Stetzik LA, et al. A novel model for neuroendocrine toxicology: neurobehavioral effects of BPA exposure in a prosocial species, the prairie vole (Microtus ochrogaster). Endocrinology. 2014; 155: 3867-3881.

95. Weiss B. The intersection of neurotoxicology and endocrine disruption. Neutotoxicology. 2012; 33: 1410-1419.

96. Galloway T, Cipelli R, Guralnik J, et al. Daily bisphenol A excretion and associations with sex hormone concentrations: results from the InCHIANTI adult population study. Environ Health Perspect. 2010; 118: 1603-1608.

97. Kundakovic M, Gudsnuk K, Franks B, et al. Sex-specific epigenetic disruption and behavioral changes following low-dose in utero bisphenol A exposure. Proc Natl Acad Sci USA. 2013; 110: 9956-9961.

98. Chevrier J, Gunier RB, Bradman A, et al. Maternal urinary bisphenol a during pregnancy and maternal and neonatal thyroid function in the CHAMACOS study. Environ Health Perspect. 2013; 121: 138-144.

99. Nakamura K, Itoh K, Yaoi T, et al. Murine neocortical histogenesis is perturbed by prenatal exposure to low doses of Bisphenol A. J Neurosci Res. 2006; 84: 1197-1205. 
100. Masuo $Y$, Ishido M. Neurotoxicity of endocrine disruptors: possible involvement in brain development and neurodegeneration. J Toxicol Environ Health B Crit Rev. 2011; 14: 346-349.

101. Elsworth JD, Jentsch JD, Vandevoort CA, et al. Prenatal exposure to bisphenol A impacts midbrain dopamine neurons and hippocampal spine synapses in non-human primates. Neurotoxicology.2013; 35: 113-120.

102. Patisaul HB, Sullivan AW, Radford ME, et al. Anxiogenic effects of developmental bisphenol A exposure are associated with gene expression changes in the juvenile rat amygdala and mitigated by soy. PLoS One. 2012; 7: e43890.

103. Adewale HB, Todd KL, Mickens JA, et al. The impact of neonatal bisphenol-A exposure on sexually dimorphic hypothalamic nuclei in the female rat. Neurotoxicology. 2011; 32:38-49.

104. Itoh K, Yaoi T, Fushiki S. Bisphenol A, an endocrine-disrupting chemical, and brain development. Neuropathology. 2012; 32: 447-457.

105. Wolstenholme JT, Rissman EF. Connelly JJ. The role of bisphenol A in shaping the brain, epigenome and behavior. Horm Behav. 2011; 59: 296-305.

106. Dolinoy DC, Huang D, Jirtle RL. Maternal nutrient supplementation counteracts bisphenol A-induced DNA hypomethylation in early development. Proc Natl Acad Sci USA. 2007; 104: 13056-13061.

107. Inadera H. Developmental origins of obesity and type 2 diabetes: molecular aspects and role of chemicals. Environ Health Prev Med. 2013; 18:185-197.

108. Yaoi T, Itoh K, Nakamura K, et al. Genome-wide analysis of epigenomic alterations in fetal mouse forebrain after exposure to low doses of bisphenol A. Biochem Biophys Res Commun. 2008; 376: 563-567.

109. Weinhouse C, Anderson OS, Jones TR, et al. An expression microarray approach for the identification of metastable epialleles in the mouse genome. Epigenetics. 2011; 6:1105-1113.

110. Kundakovic M, Champagne FA. Epigenetic perspective on the developmental effects of bisphenol A. Brain Behav Immun. 2011; 25:1084-1093.

111. De Cock M, Maas YG, van de Bor M. Does perinatal exposure to endocrine disruptors induce autism spectrum and attention deficit hyperactivity disorders? Review. Acta Paediatrica. 2012; 101: 811-818

112. Elsabbagh M, Divan G, Koh YJ, et al. Global prevalence of autism and other pervasive developmental disorders. Autism Res. 2012; 5: 160-179.

113. Moenter SM, Chu Z. Rapid nongenomic effects of oestradiol on gonadotrophin-releasing hormone neurons. J Neuroendocrinol. 2012; 24: 117-121.

114. Laredo SA, Villalon Landeros R, Trainor BC. Rapid effects of estrogens on behavior: environmental modulation and molecular mechanisms. Front Neuroendocrinol. 2014; 35: 447-458

115. Song S, Song M, Zeng L, et al. Occurrence and profiles of bisphenol analogues in municipal sewage sludge in China. Environ Pollut. 2014; 186: 14-19.

116. Vinas P, Campillo N, Martinez-Castillo N, et al. Comparison of two derivatization-based methods for solid-phase microextraction-gas chromatography-mass spectrometric determination of bisphenol $\mathrm{A}$, bisphenol $\mathrm{S}$ and bisphenol migrated from food cans. Anal Bioanal Chem. 2010; 397: 115-125.

117. Liao C, Liu F, Kannan K. Bisphenol S, a new bisphenol analogue, in paper products and currency bills and its association with bisphenol A residues. Environ Sci Technol.2012; 46: 6515-6522.

118. Liao C, Liu F, Alomirah H, et al. Bisphenol S in urine from the United States and seven Asian countries: occurrence and human exposures. Environ Sci Technol. 2012; 46: 6860-6866.

119. Grignard E, Lapenna S, Bremer S. Weak estrogenic transcriptional activities of Bisphenol A and Bisphenol S. Toxicol In Vitro. 2012; 26:727-731.

120. Molina-Molina JM, Amaya E, Grimaldi M, et al. In vivo study on the agonistic and antagonistic activities of bisphenol-S and other bisphenol-A congeners and derivatives via nuclear receptors. Toxicol Appl Pharmacol. 2013; 272:122-136

121. Helies-Toussaint C, Peyre L, Costanzo C, et al. Is bisphenol S a safe substitute for bisphenol A in terms of metabolic function? An in vitro study. Toxicol Appl Pharmacol. 2014; 280: 224-235.

122. Vinas R, Watson CS. Bisphenol S disrupts estradiol-induced nongenomic signaling in a rat pituitary cell line: effects on cell functions. Environ Health Perspect. 2013; 121: 352-358.

123. Kinch CD, Ibhazehiebo K, Jeong JH, et al. Low-dose exposure to bisphenol A and replacement bisphenol $\mathrm{S}$ induces precocious hypothalamic neurogenesis in embryonic zebrafish. Proc Natl Acad Sci USA. 2015; 112: 1475-1480.

124. Danzl E, Sei K, Soda S, et al. Biodegradation of bisphenol A, bisphenol F and bisphenol S in seawater. Int J Environ Res Public Health. 2009; 6: 1472-1484.

125. Li Y, Burns KA, Arao Y, et al. Differential estrogenic actions of endocrine-disrupting chemicals bisphenol A, bisphenol AF, and zearalenone through estrogen receptor $\alpha$ and $\beta$ in vitro. Environ Health Perspect. 2012; 120:1029-1035

126. Matsushima A, Liu X, Okada $H$, et al. Bisphenol AF is a full agonist for the estrogen receptor $E R \alpha$ but a highly specific antagonist for ER $\beta$. Environ Health Perspect. 2010; 118: 1267-1272.

127. Chamorro-Garcia R, Kirchner S, Li X, et al. Bisphenol A diglycidyl ether induces adipogenic differentiation of multipotent stromal stem cells through a peroxisome proliferator-activated receptor gamma-independent mechanism. Environ Health Perspect. 2012; 120: 984-989.

128. Riu A, le Maire A, Grimaldi M, et al. Characterization of novel ligands of ER $\alpha$, ER $\beta$, and PPAR $\gamma$ : the case of halogenated bisphenol A and their conjugated metabolites. Toxicol Sci. 2011; 122 : 372-382.

129. Riu A, Grimaldi M, le Maire A, et al. Peroxisome proliferator-activated receptor $\gamma$ is a target for halogenated analogs of bisphenol A. Environ Health Perspect. 2011; 119: 1227-1232.
130. Tontonoz P, Spiegelman BM. Fat and beyond: the diverse biology of PPARgamma. Annu Rev Biochem. 2008; 77:289-312.

131. Lu M, Sarruf DA, Talukdar S, et al. Brain PPAR- $\gamma$ promotes obesity and is requires for the insulin-sensitizing effect of thiazolodine diones. Nat Med. 2011;: 618-622

132. Ryan KK, Li B, Grayson BE, et al. A role for central nervous system PPAR- $\gamma$ in the regulation of energy balance. Nat Med. 2011; 17:623-626.

133. De Wit CA, Herzke D, Vorkamp K. Brominated flame retardants in the Arctic environment - trends and new candidates. Sci Total Environ. 2009; 408:2885-2918

134. Gallart-Ayala H, Nunez O, Moyano E, et al. Field-amplified sample injection-micellar electrokinetic capillary chromatography for the analysis of bisphenol A, bisohenol $\mathrm{F}$, and their diglycidyl ethers and derivatives in canned soft drinks. Electrophoresis. 2010; 31:1550-1559.

135. Cariou R, Antignac JP, Zalko D, et al. Exposure assessment of French women and their newborns to tetrabromobisphenol-A: occurrence measurements in maternal adipose tissue, serum, breast milk and cord serum. Chemosphere. 2008; 73: 1036-1041.

136. Johnson-Restrepo B, Adams DH, Kannan K. Tetrabromobisphenol A (TBBPA) and hexabromocyclododecanes (HBCDs) in tissues of humans, dolphins, and sharks from the United States. Chemosphere. 2008; 70: 1935-1944.

137. Ike M, Chen MY, Danzl E, et al. Biodegradation of a variety of bisphenols under aerobic and anaerobic conditions. Water Sci Technol. 2006; 53: 153-159.

138. Avissar-Whiting M, Veiga KR, Uhl KM, et al. Bisphenol A exposure leads to specific micro RNA alterations in placental cells. Reprod Toxicol. 2010; 39: 401-406

139. Meunier L, Siddeek B, Vega A, et al. Perinatal programming of adult rat germ cell death after exposure to xenoestrogens: role of microRNA miR-29 family in the down-regulation of DNA methyl-transferases and Mcl-1. Endocrinology. 2012; 153: 1936-1947.

140. Veiga-Lopez A, Luense LJ, Christenson LK, et al. Developmental programming: gestational bisphenol-A treatment alters trajectory of fetal ovarian gene expression. Endocrinology. 2013; 154: 1873-1884.

141. Vandenberg $\mathrm{LN}$, Colborn $\mathrm{T}$, Hayes $\mathrm{TB}$, et al. Hormones and endocrine-disrupting chemicals: low-dose effects and nonmonotonic dose responses. Endocr Rev. 2012; 33:378-455

142. Hoepner LA, Whyatt RM, Just AC, et al. Urinary concentrations of bisphenol A in an urban minority birth cohort in New York City, prenatal through age 7 years. Environ Res. 2013; 122: 38-44

143. Suzuki T, Mizuo K, Nakazawa H, et al. Prenatal and neonatal exposure to bisphenol-A enhances the central dopamine D1 receptor-mediated action in mice: enhancement of the methamphetamine-induced abuse state. Neurosience. 2003; 117: 639-644

144. Ryan BC, Vandenbergh JG. Developmental exposure to environmental estrogens alters anxiety and spatial memory in female mice. Horm Behav. 2006; 50: $85-93$

145. Narita M, Miyagawa K, Mizuo K, et al. Prenatal and neonatal exposure to low-dose of bisphenol-A enhance the morphine-induced hyperlocomotion and rewarding effect. Neurosci Lett. 2006; 402: 249-252.

146. Palanza P, Gioiosa L, vom Saal FS, et al. Effects of developmental exposure to bisphenol A on brain and behavior in mice. Environ Res. 2008; 108: 150-157.

147. Nakamura K, Itoh K, Yoshimoto K, et al. Prenatal and lactational exposure to low-doses of bisphenol A alters brain monoamine concentration in adult mice. Neurosci Lett. 2010; 484:66-70.

148. Martini M, Miceli D, Gotti S, et al. Effects of perinatal administration of Bisphenol A on the neuronal nitric oxide synthase expressing system in the hypothalamus and limbic system of CD1 mice. J Neuroendocrinol. 2010; 22: 1004-1012.

149. Jasarevic E, Sieli PT, Twellman EE, et al. Disruption of adult expression of sexually selected traits by developmental exposure to bisphenol A. Proc Natl Acad Sci USA. 2011; 108: 11715-11720.

150. Gioiosa L, Parmigiani S, Vom Saal FS, et al. The effects of bisphenol A on emotional behavior depend upon the timing of exposure, age and gender in mice. Horm Behav. 2013; 63: 598-605.

151. Kubo $\mathrm{K}$, Arai O, Ogata $\mathrm{R}$, et al. Exposure to bisphenol A during the fetal and suckling periods disrupts sexual differentiation of the locus coeruleus and of behavior in the rat. Neurosci Lett. 2001; 304: 73-76.

152. Aloisi AM, Della Seta D, Ceccarelli I, et al. Bisphenol-A differently affects estrogen receptors-alpha in estrous-cycling and lactating female rats. Neurosci Lett. 2001; 310: 49-52

153. Adriani W, Seta DD, Dessi-Fulgheri F, et al. Altered profiles of spontaneous novelty seeking, impulsive behavior, and response to $\mathrm{D}$-amphetamine in rats perinatally exposed to bisphenol A. Environ Health Perspect. 2003;111: 395-401.

154. Carr R, Bertasi F, Betancourt A, et al. Willard S. Effect of neonatal rat bisphenol a exposure on performance in the Morris water maze. J Toxicol Environ Health A. $2003 ; 66: 2077-2088$

155. Fujimoto T, Kubo K, Aou S. Prenatal exposure to bisphenol A impairs sexual differentiation of exploratory behavior and increases depression-like behavior in rats. Brain Res. 2006; 1068: 49-55.

156. Poimenova A, Markaki E, Rahiotis C, et al. Corticosterone-regulated actions in the rat brain are affected by perinatal exposure to low dose of bisphenol $\mathrm{A}$. Neuroscience. 2010; 167: 741-749. 
157. Ishido M, Masuo Y, Terasaki M, et al. Rat hyperactivity by bisphenol A, but not by its derivatives, 3-hydroxybisphenol A or bisphenol A 3,4-quinone. Toxicol Lett. 2011; 206: 300-305.

158. Zhou R, Bai Y, Yang R, et al. Abnormal synaptic plasticity in basolateral amygdala may account for hyperactivity and attention-deficit in male rat exposed perinatally to low-dose bisphenol-A. Neuropharmacology. 2011; 60: 789-798.

159. Xu X, Li T, Luo Q, et al. Bisphenol-A rapidly enhanced passive avoidance memory and phosphorylation of NMDA receptor subunits in hippocampus of young rats. Toxicol Appl Pharmacol. 2011; 255:221-228.

160. Fujimoto T, Kubo K, Nishikawa Y, et al. Postnatal exposure to low-dose bisphenol A influences various emotional conditions. J Toxicol Sci. 2013; 38: 539-546.

161. Evans SF, Kobrosly RW, Barrett ES, et al. Prenatal bisphenol A exposure and maternally reported behavior in boys and girls. Neurotoxicology. 2014; 45: 91-99. 